This document is provided under the UK Open Government Licence for public sector information: http://www.nationalarchives.gov.uk/doc/open-government-licence/ 


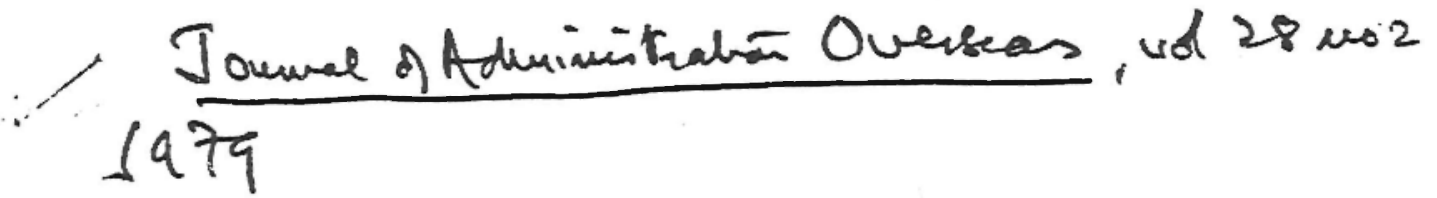

\section{Administrators: a Neglected Factor in Pastoral Development in East Africa}

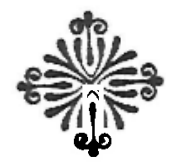

R OBERT CHAMBER $S \star \star$

Pastoral development in East Africa has been beset with many problems. Analysis of these problems has tended to concentrate on ecological, social, economic, political and rather general administrative aspects. The theme of this article is that, in addition, administrators themselves are an important but neglected factor; that they must be studied and understood as part of the system when trying to find solutions to problems of pastoral development; and that to realise the potential of administrators more fully requires a combination of research, consultancy, and training.

'Administrators' here means field government staff who work in pastoral areas. They may be at regional, provincial, district or sub-district levels. The term includes generalist administrators, and veterinary, animal husbandry, game, forestry, and other departmental staff. Typically they do not originate from the pastoral area in which they are working. 'Pastoral development' means change in pastoral areas which variously combines and reconciles (a) sustainable productivity, (b) considerations of equity, and (c) what pastoralists want.

The Neglect of Administrators

Almost any conceivable form of pastoral development, and certainly all those contemplated in East Africa, requires administrative action. Many of the components of any project or programme will rely upon it: whether surveys, planning, physical works, consultation with pastoralists, disease control, grazing rotation, stock limitation, marketing, or the provision of social services. Administrative action has many aspects, including organisation, management and politics, but here attention is focussed on the administrators themselves. They powerfully influence the nature of the official interventions which so frequently fail or lead to unintended results; and it is they who implement or fail to implement programmes or policies. When things go wrong, administrators blame pastoralists for being ignorant and stupid; and social scientists hasten to explain how the behaviour of pastoralists is rational, an able adaption to a

- This is a revised version of a paper presented to the Workshop on East African Pastoral ism organised by the International Livestock Centre for Africa and held in Nairobi on the 22-26 August 1977. The parers of the Workshop are in the process of publication by ILCA, PO Box 5689, Addis Ababa. - Robert Chambers is a Fellow of The Institute of Development Studies, Sussex. 
hostile environment. Social scientists then transfer the blame, in private conversation if not in public discussion or writing, to the administrators themselves, finding their behaviour ignorant and stupid in turn. That the behaviour of the administrators may be rational, an able adaptation to a different sort of hostile environment, may not be investigated. To the extent that this is so, one may ask whether it is not the social scientists themselves who are at fault.

For administrators are also human and a significant part of the development system; and for the future, any effective systems approach to the planning, implementation or monitoring of pastoral development must surely include them as a key factor.

It is, then, striking that there is little comparative knowledge about administrators in pastoral areas. Although administrators must be considered part of the human ecology of pastoralism, it is understandable that natural scientists should neglect them; and none of the 30 chapters in Pratt and Gwynne's Rangeland Management and Ecology in East Africa concerns itself with them. What is more surprising is that social scientists have paid them so little attention'. It has been very much the exception, not the rule, to include them in social science studies. Conrad Reining in his work on the Zande Scheme felt he was breaking new ground as a social anthropologist in the extent to which he was forced to take account of the influence of administrators, writing that

This study is unique in the degree to which it attempts to specify the influence of non-Africans in the modern African scene. I do not undertake to study British culture as such, but merely to account for changes in Zande society that have originated with the British administrators ... since some important changes have arisen almost entirely from the culture of the European administrators, with little modification from Zande culture, the administrators had to be included in the society under study. (1966:xvi)

But usually those outsiders, mainly social anthropologists, who have been closest to pastoralists and understood them best, have not been inclined to include administrators in their studies, have treated them as an exogenous variable, and have concentrated their attention almost exclusively on the pastoralists themselves.

Several explanations can be advanced for this neglect of administrators by social anthropologists. In the first place, there is a personal and diplomatic dimension. Social anthropologists work in particular areas or districts. Anything they write a oour administrators is liable to be linked with particular individuals. (Reining's extraordinary frankness about 'the second District Commissioner' may have been permitted only by the end of the colonial regime and the lapse of a decade between his fieldwork and his book.) A frank and detailed analysis might be rash

'But see Baker 1974: 3-10 for administrators' and planners' perceptions; Monod on 'Le Nomade et le Commissaire' in Monod, ed, 1975: 55-60; Spencer 1973: 168-198 for a chapter on 'The Samburu and Rendille under British Administration'; and Welch 1969 passim. To this author's knowledge, however, and with the partial exception of Welch's work, no study has yet been made of the life, work and problems of administrators in pastoral environments. 
and even subject to litigation. Moreover, to the extent that social anthropologists depend on the goodwill of administrators, they will not wish to offend them either individually or collectively, and their reluctance to criticise may be stronger to the extent that they develop friendships with them. A second explanation may be quite simply that fieldwork is exacting and generates so much information and so many questions that social anthropologists have neither time, energy nor inclination to expand their studies to include administrators. A third, and perhaps most persuasive explanation is that the administrative system is not part of the traditional concerns of ethnographic studies. It may be considered the le - $_{\text {inate }}$ study not of social anthropology but of public administration and political science.

But students of public administration and political science have also tended to ignore administrators in pastoral areas. There have been studies of rural administration (for example, in Hyden et al. 1970, and Leonard 1973) and many of agricultural extension. But only one, to my knowledge, deals specifically with administrators in a pastoral area, and this - Calvin Welch's thesis on pastoralists and administrators in Karamoja (1969) - is unpublished.

Again, reasons for this lack of research are not difficult to see. Pastoral areas are often remote and inaccessible. Administrators there are more difficult to study than administrators in settled agricultural areas. The great majority of students may anyway prefer to work in settled agricultural areas if these are the areas from which they originate and with which they feel familiar. Social scientists, especially students, tend prudently to study what is studiable and physically less exacting. In these circumstances, it is perhaps not to be wondered at that so little that is relevant has been written.

Given the factors which deter social scientists from studying and writing about administrators, there is a danger of repeatedly aiming research at lower priority targets. Professionals are tempted to cross the t's and dot the i's of existing paradigms and concerns while leaving expanses of: ignorance untouched. Peter Rigby is by no means unusual in having called for more sociological research without specifying that it should be directly related to the political and planning problems which he identifies. In his paper on 'Pastoralism and Prejudice', he has written:

If livesinck development is to become a major tool in rural development, much more sociological research of an intensive kind would pay handsome dividends. I have suggested that there are, however, deep-seated political and planning problems involved. Some of these problems are a legacy we have inherited from the colonial regimes. But others stem from unformalised but persistent prejudice, particularly at local administrative and 'popular' levels against pastoral and semi-pastoral peoples. This suggests that the planning and administrative hierarchies are insufficiently coordinated to translate enlightened attitudes and policies on pastoral development into action at the local level. (n.d. 51)

This is, of course, only one paragraph from a long paper. But it does illustrate the tendency. Sociological research implies research on the pastoralists not on the administrators. But pastoralists in East Africa are relatively well understood by 
social scientists. The main problem is to see how to make the insights of social scientists accessible to administrators and how, appropriately, to influence their attitudes and behaviour. For that, an understanding of administrators themselves is needed, and it is towards them that research should be directed.

As long as we remain largely ignorant of administrators and their environments, there are two dangers.

The first danger is the ease of thinking of them in terms of uncomplimentary stereotypes as ignorant, arrogant and arbitrary in their actions. It must be admitted that in both the colonial and the post-colonial periods, the actions and attitudes of administrators have quite often seemed to justify those epithets. Examples can be found in the long list of failures in pastoral management and of failures to learn from failures; in the recurrent reflex to compel pastoralists to settle and grow crops, regardless of whether this would be sound land use, whether crops would grow, or whether people would want to settle; in alternations between indifference and laissez-faire policies on the one hand, and resort to force and compulsion on the other; in the continuing practice of putting in more water without measures to sustain the productivity of the range made accessible by that water; in what sometimes appears a perverse refusal to grasp the rationality of nomadism. I have myself as an administrator been guilty of some of these errors and now, looking back, am staggered at my blindness and at a loss to understand how I could have been so deluded. The puzzle and the challenge here are to try to understand why administrators behave as they do; and why they believe what they believe. Administrators may indeed, in their ignorance, be prejudiced about pastoralists but so too may social scientists, in their ignorance, be prejudiced about administrators. The stereotypes of administrators may be built up and reinforced not by research but by anecdotes selected because they make good stories, quoting the quotable, as is done, be it noted, in this paper. There is, however, no a priori reason to suppose that administrators' behaviour is any less rational, given their environments, than is pastoralists', given theirs. Only when knowledge of that rationality replaces prejudice will it be possible to see how they, the administrators, can be influenced to behaviour differently.

The second danger is that we will continue to ignore the administrative factor in planning for pastoral development. John Howell, writing of the Western Sudan, has argued the need as part of the planning process for an 'administrative resource survey'. He asks:

What institutions for implementation exist at local level? What is the 'carrying capacity' of the local administration? How far can the structure of central, provincial, district and local council administration enhance the prospects for detailed development planning? How are planning decisions taken? What is the existing strength of professional field staffs? It is only after answers to these questions have been attempted that the development plan itself can be appraised and an institutional strategy for implementation be considered. It is not enough to conjure up some ideas on implementation simply as an afterthought to the recommendations based on an integrated resource survey. The administrative 'mapping' must be part of the development plan itself. (1977:106) 
An administrative resource survey in pastoral areas might frequently reveal systemic problems which would limit and condition what could be attempted; and in the absence of such a survey, proposals drawn up are likely to be unrealistic.

\section{Factors Affecting Administrators}

Ignorant though we are, scartered evidence and impressions can be drawn together to suggest four clusters of factors which especially affect the motivation, behaviour and perceptions of administrators; and these four also constitute a partial agenda for future research. They.are:

$$
\begin{aligned}
& i \text { transfers and continuity; } \\
& \text { ii difficult and unpopular postings; } \\
& \text { iii administrative convenience; } \\
& \text { iv encapsulation and belief systems. }
\end{aligned}
$$

\section{i transfers and continuity}

To the extent that pastoral development requires confidence and mutual understanding between pastoralists and administrators, continuity of contact will be an important element in success. Such continuity may be all the more important when the pastoralists distrust the administrators and the administrators misperceive or misunderstand the pastoralists. Of late colonial grazing schemes in Kenya, Richard Hennings wrote that if there was little prospect of staff continuity over, say, the first five years, it was probably better not to start at all; and that the surest key to success in the early stages at least was to have the right officer actually living in the area (1961:68). This is borne out by the experience in Kenya in the late 1950s and early 1960s: grazing schemes enjoyed apparent success in West Pokot District with the same officer in charge for the better part of a decade, but fared worse elsewhere where there were staff changes.

There was probably greater continuity in field posts during the late colonial period than there has been since. The period of de-Europeanization and Africanization was inevitably a time of very rapid transfers which have since moderated but probably stabilized at a higher rate of turnover than before. The evidence is scattered but consistent. For Southern Darfur Province in Sudan, John Howell reports 'a record of high staff turnover' (1977:177). For the Taita and Kaputiei Schemes in Kenya, Morag Simpson observes that 'a very heavy responsibility falls on the Range Management Division's local range officers.... They are ... liable to be transferred from one part of Kenya to another and their period of service in any one location is ofren less than a year' (1973:15). At a District Development Committee meeting which I attended in 1970 in Samburu District in Kenya and which had before it as the major item on the agenda a land use plan for part of the district, only one of the ten or so government officers present had been in the District for more than a year. Indeed, Jon Moris, having worked for some years in a pastoral area of Tanzania, has suggested 
that frequent transfers may now be systemic in East African administrations. He has put forward the view that they are linked with a lack of effective control systems for top officials who then use the transfer of subordinates as 'the main administrative solution to almost every problem' (1977:79). If this is so, then there may be only very temporary and superficial contact between what are often two systems of nomadism - that of the pastoralist and that of the administrator - with neither trying to invest in understanding the other but merely trying to capitalise on what both recognise as a transient relationship. Such a situation severely limits the types of initiatives which can be contemplated in pastoral development.

\section{ii difficult and unpopular postings}

In both colonial and post-colonial East Africa, administrators have usually come from cultural backgrounds alien to those of pastoralists themselves. The three main groups are expatriate colonial administrators; expatriate technical assistance personnel; and now most importantly, African administrators from a nonpastoral background.

Expatriate colonial administrators were, of the three groups, probably the most satisfied with their postings and the life it entailed. Most of these administrators in East Africa were people who had chosen to live and work away from their home country and who expected and were prepared for unfamiliar experiences. Those who worked in pastoral areas were partly self-selected because they preferred the sort of life entailed. Some like Charles Chenevix Trench (1964) revelled in the opportunity for a physically exacting, unconventional and hard life in remote areas. Many, perhaps most, of the colonial administrators who worked in pastoral districts did so in preference to work in settled agricultural districts.

With technical assistance personnel and volunteers the pattern is by no means so clear. Quite often, it seems, they have been unprepared or unsuitable. The evidence is scattered, incomplete and anecdotal, as with three USAID-funded technicians who had to be removed from Tanzanian Masailand and returned to the United States (Hess 1976:22). A strange and perhaps extreme example is presented by the American Peace Corps volunteers who worked in range management in Kenya, of whom Morag Simpson has written that this struck her as

... the most bizarre feature of the whole operation. The Peace Corps consists of young men newly graduated, usually with neither ranching nor African experience. These unfortunate people were sent into the wilds of Taita and Raputiei after a brief initiation course to camp under canvas in the locations where ranches are planned. They were supposed to organise the local people and then become the managers of the ranches when they started. One cannot but be sorry for them; camping in a strange environment, often sick from insect bites, food and water infections, surrounded by wild animals and snakes, with curious Africans watching them yet unable to communicate with these other human beings owing to their ignorance of the local languages. It is not surprising that some of these young men left, not being able to stand the conditions. It is remarkable that one or two made a success of their mission. (Simpson 1973:16) 
In general, technical assistance personnel and volunteers probably experienced more severe shocks and found their postings and work more difficult than had expatriate colonial administrators who had a longer acclimatization and more clearly defined roles.

By far the most important group is African administrators who come from a non-pastoral background. (Partly because of relatively low educational standards among pastoral peoples, most administrators are probably not from pastoral but from settled agricultural backgrounds.) For them, it seems, postings to pastoral areas, epecially when these are remote, are usually unpopular. The reasons include:

- the use of such posts for penal purposes for those who have in some way misbehaved or fallen from favour, or for those who are politically weak and least able to resist. (This also occurred in the colonial period.);

- the distance from the capital where transfers and promotions are decided;

- difficulties with children's education and often the need to leave children in school elsewhere in the country, with consequent family disruption and cost;

- physical factors such as climate and diet;

- distaste for extensive travel and camping out;

- social isolation in what is perceived as an alien culture;

- lack of urban amenities;

- inadequate transport.

One consequence may be that administrators spend much of their time on activities unrelated to pastoral development. They may make frequent and prolonged visits on various pretexts to regional headquarters and to capital cities, both for social reasons and in order to campaign for a more congenial posting. A high proportion of their transport votes may go on these trips, curtailing their ability to travel locally. In the pastoral area itself they may devote much effort and imagination to improving their conditions. As Calvin Welch has pointed out in his description of the District Team in Karamoja in 1968, they may form a pressure group. His example may be extreme, but it does give the flavour of administrators' concerns in somewhat isolated posts. The District Team, he says, was 'wholly a creature of the local representatives of the various Ministries of the Central Government'. He goes on

In March, the Team devoted a large portion of its meetings to 'allowances in relation to costs in Karamoja'. Topics under consideration at that time were the price of matoke, the poor quality of fresh milk, the high price of petrol in Moroto, the inadequacy of the 'up country' living allowance, the ansence oi 'price control' in the District with the resultant effect being (in the eyes of the Team) that 'the Civil Servant in Raramoja was the Victim' (capitalization in the original)... In Octobes of 1968, a discussion was centred around a TV station for Moroto. The Team felt that 'in view of the fact that the number of TV owners in Moroto had increased tremendously' a TV station should be built in Moroto, or failing that, 'a TV repairman should visit Moroto as often as possible'. This over-concern with creature comforts of the Civil Service shown by the District Team, while being understandable, is nonetheless indicative of the Team's total unawareness of the major groblems of the District. Indeed, ... the Team was willing to close the only agricultural training establishment in the entire District if it meant by so doing that they could get fresh milk delivered in Moroto... (Welch 1969:218-9) 
The importance of this example is not that it necessarily indicates a general condition, at least in such an extreme form, but that it does contribute to an agenda for research. If African administrators from non-pastoral backgrounds dislike their postings, this is liable to influence their attitudes and behaviour. Only by understanding their problems and motivations and the rationality of their behaviour given their environments will it be possible realistically to identify measures for improvement.

iii administrative convenience

Administrators' behaviour is partly determined by convenience. Their tasks, of course, vary by department and by district. There is, however, a recurrent tension between what is convenient to the administrator and what is convenient to the pastoralist. Administrators like fixed locations. They often concentrate their attention on site-bound activities - the building of schools, health centres, dams, boreholes, government offices, roads, crushes, and the like. These are conveniently static, and being physical, are visible and even photogenic and can be shown to visitors as evidence of progress. They are also, of course, often badly needed. But this preference for the physically fixed carries over into prescriptions for the human and animal population. The persistent view that pastoralists should be made to settle in one place may reflect not only a cultural preference for settled agriculture but also a desire for administrative convenience. Those who are settled are more easily regulated, taxed, protected, and even fed in times of: famine. But those who settle in small centres may be atypical: the very rich, who can afford to abandon nomadism and the very poor who cannot afford to continue it. The great majority of the population may continue its nomadic way of life under pressure from the imperatives of a marginal environment, inconveniently out of touch for site-bound administrators. Convenience keeps administrators and pastoralists apart.

iv encapsulation and belief systems

Administrators who are alien to a pastoral environment may be especially vulnerable to encapsulation and to belief: systems composed largely of myths. The encapsulation is both physical and cognitive. Physically, they may be almost entirely confined to their houses, offices and vehicles, with little or no direct exposure to the world of the pastoralists. Cognitively, they may seek out, be exposed to, and be presented with, highly selective information. In particular, all or almost all those with whom they come into contact will have special reasons for presenting slanted or selected information and impressions. Those government staff who originate from the local pastoral population are ofren caught in an awkward intercalary position, 'the nut in the nutcracker' (Welch 1969:200), between administrators on the one hand, and pastoralists on the other, and may try to sustain their position by presenting to the administrators information which provides 'evidence' for what the administrators want to believe. The administrators themselves may have what Dahl and Hjort call an 'anti-nomad ideology' (1976:18) supported by misconceptions about pastoralists. The outcome can be the coexistence of two beliefisystems about the same reality: that of the administrators; and that of the pastoralists themselves. This appears 
to have been true in the colonial period as well as today. Thus of the earlier period, Paul Spencer found

two sets of values with little in common (save mutual goodwill on both sides) and two worlds of reality coexisting in one district' (1973:174)

and of more recent situations, Randall Baker has similarly observed that

there exist two separate worlds, those of the planner and the planned; divided by a gulf of perception. The failure to bridge this gulf is a major contributory factor to the deplorable state o. frica's rangeland at the present time as well as to the distressing impasse which exists between stock keeper and administrator, planner or visiting expert. (n.d. 360)

In making generalisations such as these there are also dangers. It has to be asked whether our perceptions are selective; whether we collect and remember anecdotes which show administrators in a poor light; whether failures receive more attention than successes; and whether pastoral development is not inherently so difficult that there is a persistent tendency to place the blame for shortcomings on administrators who are, in a situation of widespread ignorance even on the part of the 'experts', attempting what is virtually impossible. But administrators may be behaving rationally, and they need their belief systems just as, in their different ways, pastoralists are behaving rationally and need theirs; and administrators, like the pastoralists and pastoral situations with which they deal, are not all the same. Depressing though the general impression may be, particular cases may be more encouraging.

\section{A Direction for Solutions}

The solutions sought depend on the problems identified. The problems identified depend, in turn, upon the discipline and viewpoint of the observer. The multifeceted nature of pastoral situations and pastoral development needs no emphasis. But what the tentative assertions above suggest is that, in the sphere of planning and implementation, something more may be needed than conventional prescriptions. It takes us some way to identify, as Randall Baker has done, that there is an administrative trap: that different departments handle different sectors, and that the social aims and norms of the pastoralists are neglected because no department is competent to deal with them (Baker 1975). But one has to ask who is to assess and represent within the planning bureaucracy those social aims and norms, and how it can be made possible and rational for them to do so. Those most suitable may well be those who claim the right: the generalist administrators who, in departmental debate, use as a trump card their opinions about what is politically feasible, and what the people will accept or can be persuaded to do. This, then, leads us back to the perceptions and behaviour of those generalist administrators, and the four adverse conditions of lack of continuity in post, of difficult and unpopular postings, of administrative convenience, and of encapsulation and misleading beliefs.

The most effective solution to these four problem areas may lie, as with much management development, in a combination of research, consultancy and training. 
Research appears necessary in order more systematically and fully to understand the life, work, perceptions and beliefs of administrators; it is particularly needed because administrators who work with pastoralists appear to have been less studied and less understood than those who work in areas of settled agriculture, and because social scientists' views of such administrators, starting from the effects of their actions on pastoralists, have tended to be unsympathetic. For reasons which parallel those for the persistence of technical assistance and for the unpopularity among national administrators of work in pastoral areas, almost all the research on pastoral systems that has been written up has so far been by non-nationals, as reflected in the references to this paper. In addition to other powerful reasons for future research by nationals, the study of administrators may be an area where they have a strong comparative advantage over non-nationals in ease and accuracy of understanding and interpretation.

Consultancy appears necessary because some of the problems are systemic. If frequent transfers and unpopular postings are a serious and endemic problem, then management consultancy within or for the government concerned will be needed, together with progressive administrative changes, if the problems are to be reduced or overcome. Questions of selection and induction of suitable staff may emerge as critical.

Training appears necessary because of administrators' misperceptions of pastoralism and of pastoralists and because of the misprescriptions which flow from them. The assumption here is that better understanding on the part of administrators would improve their own actions and make pastoral development at least less unlikely.

These three approaches are mutually supporting. Together, they are greater than the sum of their parts. Any organisation undertaking them has to be versatile and credible. It may be that this would be difficult, in most countries, for any national organisation on its own. In Kenya, Tanzania, and Uganda, for example, predominantly pastoral districts are a minority and might not justify using national resources to mount a special programme. Perhaps the International Livestock Centre for Africa could develop such a capability for research and consultancy and conduct training partly through national institutes of administration or agricultural training organisations. The tasks are intimidating and the risks high. But if the argument of this paper is correct, many of the problems in pastoral development he in the administrators themselves and in the administrative environment in which they operate; and unless these problems are understood and overcome, the prospects for pastoral development in much of East Africa may well remain poor.

\section{References}

BAKER, Randall, 1974 'Perceptions of Pastoralism', Development Studies Discussion Paper, No 3, Overseas Development Group, University of East Anglia.

- 1975 'The Administrative Trap', Development Studies Discussion Paper, No 5, School of Development Studies, University of East Anglia. 
- n.d. 'The Social Importance of Cattle in Africa and the Influence of Social Attitudes on Beef Production' (publication details not known)

CHEVENIX TRENCH, Charles, 1964 The Desert's Dusty Fare, Blackwood, Edinburgh and London.

DAHL, Gudrun and Anders Hjort, 1976 Having Herds: Pastoral Herd Growth and Household Economy, Department of Social Anthropology, University of Stockholm.

HENNINGS,R. C., 1961 'Grazing Management in the Pastoral Areas of Renya', fournal of African Administration, Vol 13, No 4, October.

HESS, Oleen, 1977 'The establishment of Cattle Ranching Associations among the Masai in Tanzania', Rural Development Committee Occasional Papers, No 7, Cornell University, Ithaca.

Howell, John, 1977 'Administration and Rural Development Planning: a Sudanese Case', Agricultural Administration, Vol 4, No 2, April, pp 99-120.

HYDEN, Goran, Robert Jackson and John Okumu, eds., 1970 Development Administration: the Kenyan Experience, Oxford University Press, Nairobi.

LEONARD, David K., ed., 1973 Rural Administration in Kenya, East African Literature Bureau, Nairobi, Kampala, Dar es Salaam.

MONOD, Theodore, ed., 1975 Pastoralism in Tropical Africa, Oxford University Press for the International African Institute, London, Ibadan, Nairobi.

MORIS, Jon R., 1977 'The Transferability of Western Management Concepts and Programs, an East African Perspective' in Stifel et al. eds.

PRATT, D. J. and M. D. Gwynne, eds., 1977 Rangeland Management and Ecology in East Africa, Hodder and Stoughton, London, Sydney, Auckland, Toronto

REINING, Conrad C., 1966 The Zande Scheme: an anthropological case study of economic development in Africe, Northwestern University Press, Evanston.

RIGBY, Peter n.d. 'Pastoralism and Prejudice: ideology and rural development in East Africa', Nkanga, Makerere University College, No 4, 'Society and Social Change in Eastern Africa'. SimpSON, Morag C., 1973 'Alternative Strategies for Range Land Development in Kenya', Rural Development Study No 2, Department of Agricultural Economics, University of Leeds. SPENCER, Paul, 1973 Nomads in Alliance: Symbiosic and growth among the Rendille and Samburu of Kenya, Orford University Press, New York, Toronto, Nairobi.

STIFEL, Laurence D., James S. Coleman and Joseph E. Black, eds., 1977 Educarion and Training for Public Sector Management, The Rockefeller Foundation.

WELCH, C. P., 1969 'Pastoralists and Administrators in Conflict: a Study of Karamoja District, 1897-1968', unpublished MA Thesis, University of East Africa, Makerere. 